\title{
Three styles of diamond resorption in a single kimberlite: Does crustal xenolith assimilation play a role?
}

\author{
Yana Fedortchouk ${ }^{1}$, Ingrid L. Chinn', Maya G. Kopylova ${ }^{3}$ \\ ${ }^{I}$ Dalhousie University, Halifax, Canada, yana@dal.ca \\ ${ }^{2}$ De Beers Exploration, Johannesburg, South Africa, Ingrid.Chinn@debeersgroup.com \\ ${ }^{3}$ University of British Columbia, Vancouver, Canada, mkopylov@eos.ubc.ca
}

\section{Introduction}

Many features of kimberlites indicate explosive eruptions and high content of volatiles. Theoretical modelling and experimental estimates of volatile solubility in kimberlite-like melts are the two main approaches used to constrain exsolution of fluid during kimberlite ascent. Both approaches are hampered by the unknown composition of kimberlite melts. Here, we present a new method for investigating the kimberlitic fluid by using direct evidence from diamond resorption features. Experiments show that diamond interaction with $\mathrm{H}_{2} \mathrm{O}$-rich or $\mathrm{CO}_{2}$-rich fluids, and with volatileundersaturated melts produce contrasting resorption features on diamonds. We use 802 diamonds (> $0.5 \mathrm{~mm}$ ) collected in restricted depth intervals in three drillholes from BK1 kimberlite and one drillhole in AK15 coherent kimberlite (Orapa cluster, Botswana). The diamond data and depth ranges can be found in Table 1 and Fig. 1. In BK1 kimberlite, the drillholes sampled three kimberlite lithologies: coherent kimberlite CK-A, coherent kimberlite CK-B, and a volcaniclastic kimberlite (MVK). We also examined 70 thin-sections from the same drillholes to compare the fluid record in diamond resorption features with the kimberlite textures. The robust geological control on the diamond samples provides a unique opportunity to reconstruct the composition and the parameters of exsolution for magmatic fluid in these kimberlite lithologies.

\begin{tabular}{llllll} 
Kimberlite & BK1 & BK1 & BK1 & AK15 & TOTAL \\
\hline Drillhole & H005 & H007 & H008 & H001 & \\
Depth interval (m) & $0-164$ & $0-200$ & $0-200$ & $0-163$ & \\
Kimberlite facies & CK-A & MVK & CK-B & CK & \\
Diamonds total & 169 & 294 & 192 & 357 & $\mathbf{1 , 0 1 2}$ \\
Diamonds studied & 169 & 190 & 168 & 275 & $\mathbf{8 0 2}$ \\
\hline Resorption: & & & & & \\
Kimberlite-induced resorption & 28 & 37 & 90 & 78 & $\mathbf{2 3 3}$ \\
Kimberlitic - mantle combined & 34 & 7 & 18 & 40 & $\mathbf{9 9}$ \\
Mantle-derived resorption & 61 & 30 & 14 & 59 & $\mathbf{1 6 4}$ \\
Undefined morphology & 46 & 116 & 46 & 98 & $\mathbf{3 0 6}$
\end{tabular}

Table 1: Macro-diamond samples from four drillholes in BK1 and AK15 kimberlites showing the proportion of diamonds with different origin of resorption (CK-coherent kimberlite, MVK-massive volcaniclastic kimberlite).

\section{Diamond resorption in kimberlite magma and inherited from the mantle}

Each of the studied diamond parcels from the four lithologies has one unique resorption style that is 1) the most common for this parcel, 2) present on all rounded tetrahexahedral (THH) diamonds, 3) present on the rounded sides of pseudehemimorphic diamonds, 4) shown by diamonds attached to kimberlite, and 4) developed along the edges of diamonds with combination of two resorption styles. We can confidently conclude that this specific resorption style represents kimberlite-induced resorption, while any other resorption style in the same parcel is inherited from the mantle. Diamonds with only kimberlitic resorption comprise $\sim 25 \%$ in CK-A lithology, $\sim 50 \%$ in MVK and AK15 samples, and $\sim 75 \%$ in CK-B lithology (Fig. 1). All parcels show an increase in the intensity of kimberlite-induced resorption with drill hole depth (Fig. 1), and this is especially evident in the MVK and AK15 parcels. 


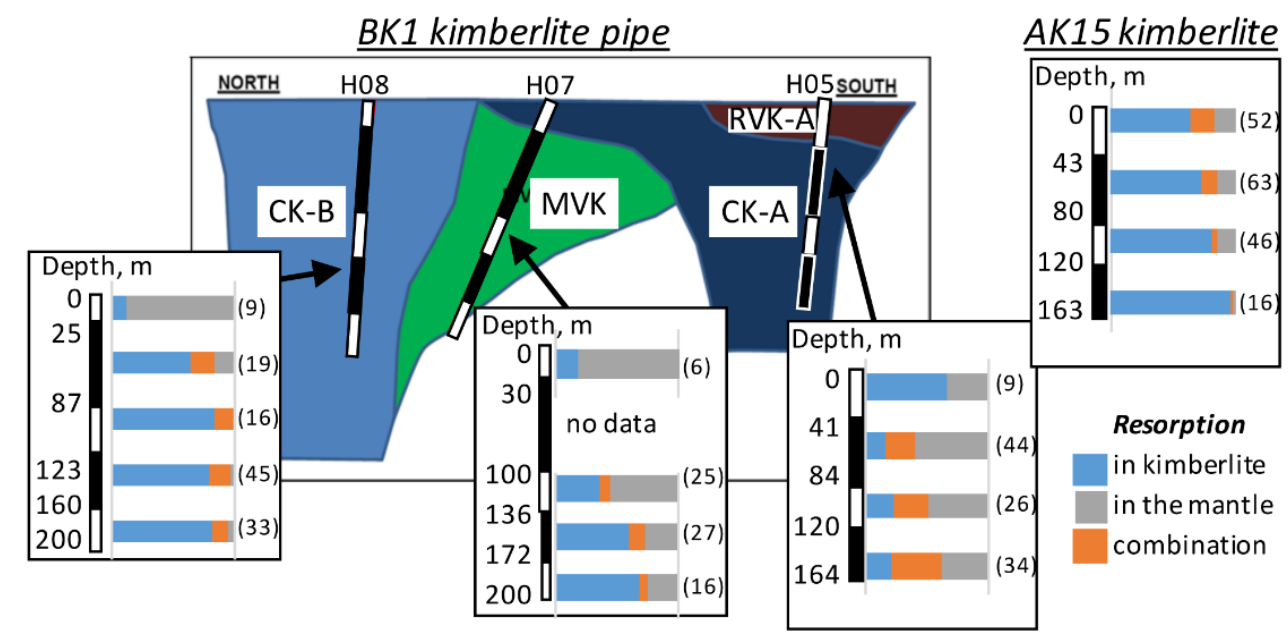

Figure 1: Cross-section of BK1 pipe and position of drill holes in the two lobes filled with coherent CK-A and coherent CK-B kimberlites, and in a pyroclastic kimberlite (MVK) between these lobes. AK15 has one coherent lithology. The inserts show the proportions of diamonds with kimberlite-induced and mantle-derived resortion, and with a combination of both resorption styles with depth in each lithology. The number of diamonds studied in each depth interval is given in brackets.

\section{Three styles of kimberlite-induced resorption in BK1 pipe}

Kimberlite-induced resorption is different in the three lithologies from BK1 kimberlite (Fig. 2). MVK diamonds developed glossy well rounded surfaces (Fig. 2A), which are similar to the diamonds from volcaniclastic kimberlites in other localities and resemble experimental products of diamond dissolution in $\mathrm{H}_{2} \mathrm{O}$-rich fluid (Fedortchouk et al., 2010). Very similar kimberlitic resorption is observed in CK-A lithology, but these diamonds exhibit chains of micro-cavities with a diameter of 5-15 $\mu \mathrm{m}$ (Fig. 2B). Most distinctive is the kimberlite-induced resorption on CK-B diamonds, which yielded severely corroded rounded crystals (Fig. 2C) resembling experimental products of diamond dissolution in carbonate melt (Zhang et al., 2015). SEM imaging revealed similarities between the corroded surfaces of CK-B diamonds and micro-cavities on CK-A diamonds, implying that these cavities represent an initial stage of the same resorption event that affected CK-B diamonds. Surprisingly, resorption in the coherent AK15 kimberlite is identical to that of the MVK samples from BK1 in style and intensity.
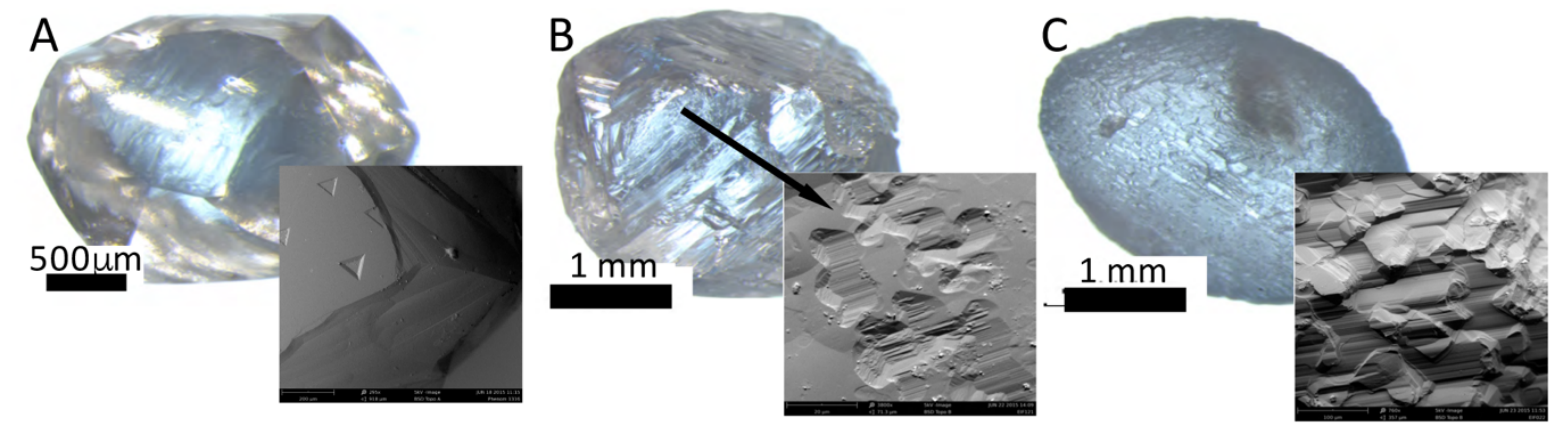

Figure 2: Microphotographs and secondary electron (SEM) images of kimberlite-induced resorption: A - glossy or frosted THH with thin striations, and negatively oriented trigons in BK1 MVK and in AK15; B - similar glossy THH with "chains" of micron-size cavities in CK-A; C - THH with extremely rough corroded surfaces in CK-B.

\section{Kimberlite textures}

The kimberlite textures show contrasting features in BK1 lithologies. CK-B is the only lithology with no segregations in the groundmass, no magmaclasts or other indicators of fragmentation. In contrast, CK-A is a coherent macrocrystic kimberlite showing segregationary groundmass formed via fluid exsolution and local development of diffuse magmaclasts. MVK and AK15 also demonstrate textures indicative of fluid exsolution, i.e. magmaclastic texture in MVK with classic "pelletal lapilli" and 
segregationary groundmass in AK15. Crustal xenoliths (mostly Karoo basalts) are common in MVK $(\sim 30 \%)$ and in AK-15 where they increase in abundance with drill hole depth from $5 \%$ to $60 \%$. All xenoliths/xenocrysts are mantled by rims of fibrous clinopyroxene. CK-B contains $1-3 \%$ of totally digested Karoo xenoliths appearing as patches of serpentine. CK-A contains no crustal xenoliths.

\section{The role of fluid}

The different role of volatiles in the three BK1 litholgies is supported by both diamond resorption and kimberlite petrography. The CK-B unit reached the surface as a volatile-undersaturated melt (confirmed by the corrosive diamond resorption and the absence of segregationary groundmass textures). Its slow ascent in the absence of fluid phase explains the intensive kimberlite-induced resorption (Fig. 1). MVK magma reached the surface fragmented as seen in the presence of magmaclasts, with abundant free fluid as evidenced by glossy diamond resorption. Exsolution of fluid in CK-A unit is also confirmed by the glossy diamond resorption and segregationary groundmass textures, while the diamonds also record the second resorption event in volatile-undersaturated melt. The similarity of diamond resorption and groundmass textures in pyroclastic MVK and coherent CK-A units suggests that CK-A represents either a reconstituted (welded or cintered) clastogenic lava (Hayman et al., 2008) or a frozen volcanic degassing front (Hetman et al., 2004). The petrography of CK-A does not support reconstitution model but is compatible with the origin of CK-A and MVK units from a single batch of fluid-oversaturated magma which experienced local degassing. The CK-B unit was formed from a different fluidundersaturated magma batch. In AK15 groundmass textures contradict reconstitution of extrusive magma and glossy diamond resorption must have been caused by magmatic fluid insufficient for fragmentation.

$\mathrm{H}_{2} \mathrm{O}$ and $\mathrm{CO}_{2}$ reach saturation in kimberlite magma only within the last $2.5 \mathrm{~km}$ of ascent (Moussallam et al., 2016). The high proportion of rounded THH diamonds and the character of resorption on BK1 and AK15 diamonds require fluid presence at a much greater depth ( $>1 \mathrm{GPa}$ (Zhang et al., 2015). $\mathrm{CO}_{2}$ degassing can be triggered by dissolution of silicate-rich material in carbonate-rich magma. Reaction between mantle orthopyroxene and kimberlite melt can start as deep as at $2.5-3.5 \mathrm{GPa}$ (Stone et al., 2016). Reaction of kimberlite magma with silicic crustal xenoliths through the tens of kilometers of crust would depend on the volume of crustal xenoliths entrained and assimilated by different portions of the rising kimberlite. Indeed, both units with glossy diamonds, BK1 MVK and AK15, demonstrate significant assimilation of Karoo basalts. CK-A and CK-B lithologies in BK1 have diamonds with corrosive (melt) features and very few assimilated xenoliths. Our work shows that diamond resorption morphology provides a robust record of fluid exsolution during magma emplacement. Reactions of kimberlite melt with mantle orthopyroxene, crustal xenoliths, and decompressional degassing provide three mechanisms for fluid exsolution at progressively shallower depths. We propose that the depth of fluid exsolution and its retention by the melt plays an important role in diamond preservation.

\section{References}

Fedortchouk Y, Matveev S, Carlson JA (2010) $\mathrm{H}_{2} \mathrm{O}$ and $\mathrm{CO}_{2}$ in kimberlitic fluid as recorded by diamonds and olivines in several Ekati diamond mine kimberlites, NWT, Canada. Earth Plan Sci Let 289:549-559.

Hayman PC, Cas RAF, Johnson M (2008) Difficulties in distinguishing coherent from fragmental kimberlite: a case study of the Muskox pipe (Northern Slave Province, Nunavut, Canada): J. Volcanol. Geotherm. Res.174:139-151.

Hetman CM, Scott Smith BH, Paul JL, Winter FW (2004) Geology of the Gahcho Kue kimberlite pipes, NWT, Canada: root to diatreme magmatic transition zones. Lithos 76:51-74

Moussallam Y, Morizet Y, Gaillard F (2016) $\mathrm{H}_{2} \mathrm{O}-\mathrm{CO}_{2}$ solubility in low $\mathrm{SiO}_{2}$-melts and the unique mode of kimberlite degassing and emplacement: Earth Plan Sci Let 447:151-160.

Stone RS, Luth RW (2016) Orthopyroxene survival in deep carbonatite melts: implications for kimberlites. Contrib Mineral Petrol:171:63

Zhang Z, Fedortchouk Y, Hanley JJ (2015) Evolution of diamond resorption in a silicic aqueous fluid at 1-3 GPa; application to kimberlite emplacement and mantle metasomatism: Lithos 227:179-193. 